\title{
Prevalence of chronic pain, posttraumatic stress disorder, and persistent postconcussive symptoms in OIF/OEF veterans: Polytrauma clinical triad
}

\author{
Henry L. Lew, MD, PhD; ${ }^{1-3^{*}}$ John D. Otis, PhD; ${ }^{4}$ Carlos Tun, MD; ${ }^{1-2}$ Robert D. Kerns, PhD; ${ }^{5}$ Michael E. \\ Clark, PhD; ${ }^{6}$ David X. Cifu, MD $^{7}$ \\ ${ }^{1}$ Physical Medicine and Rehabilitation (PM\&R) Service, Department of Veterans Affairs (VA) Boston Healthcare System, \\ Boston, MA; ${ }^{2}$ Harvard Medical School, Boston, MA; ${ }^{3}$ Defense and Veterans Brain Injury Center (DVBIC) Site, Boston, MA; \\ ${ }^{4}$ Pain Research Program, VA Boston Healthcare System, Boston, MA; ${ }^{5}$ PRIME Center, VA Connecticut Healthcare System, \\ West Haven, CT; ${ }^{6}$ Chronic Pain Rehabilitation Program, James A. Haley Veterans' Hospital, Tampa, FL; ${ }^{7}$ PM\&R Service, \\ Richmond VA Medical Center, Richmond, VA
}

\begin{abstract}
This study examines the prevalence and coprevalence with which returning Operation Iraqi Freedom (OIF)/ Operation Enduring Freedom (OEF) veterans were reporting symptoms consistent with chronic pain, posttraumatic stress disorder (PTSD), and persistent postconcussive symptoms (PPCS). The medical records of 340 OIF/OEF veterans seen at a Department of Veterans Affairs Polytrauma Network Site were comprehensively reviewed. Analyses indicated a high prevalence of all three conditions in this population, with chronic pain, PTSD, and PPCS present in $81.5 \%, 68.2 \%$, and $66.8 \%$, respectively. Only 12 of the veterans (3.5\%) had no chronic pain, PTSD, or PPCS. The frequency at which these three conditions were present in isolation $(10.3 \%, 2.9 \%$, and $5.3 \%$, respectively) was significantly lower than the frequency at which they were present in combination with one another, with $42.1 \%$ of the sample being diagnosed with all three conditions simultaneously. The most common chronic pain locations were the back (58\%) and head (55\%). These results underscore the complexity of the presenting complaints in OIF/OEF veterans and support the importance of a multidisciplinary team approach to assessment and treatment.
\end{abstract}

Key words: brain injuries, explosions, Iraq, military personnel, pain, posttraumatic stress disorder, rehabilitation, veterans, war, wounds and injuries.

\section{INTRODUCTION}

Advances in battlefield medicine and protective armor for the torso have led to a higher percentage of soldiers surviving physical injuries that would have been fatal in prior conflicts [1-3]. Many of these injuries sustained from the current conflict in the Middle East have been described as "polytrauma," defined by the Veterans Health Administration (VHA) as "two or more injuries to physical regions or organ systems, one of which may be life threatening, resulting in physical, cognitive, psychological, or psychosocial impairments and functional disability." While the concomitant injuries accompanying traumatic brain injury (TBI) may be manifold, including fractures, amputations, burns, spinal cord injury, eye injury, and auditory trauma,

Abbreviations: $\mathrm{OEF}=$ Operation Enduring Freedom, OIF = Operation Iraqi Freedom, PNS = Polytrauma Network Site, PPCS $=$ persistent postconcussive symptoms, PRC $=$ Polytrauma Rehabilitation Center, PTSD = posttraumatic stress disorder, $\mathrm{TBI}=$ traumatic brain injury, $\mathrm{VA}=$ Department of Veterans Affairs, VHA = Veterans Health Administration.

*Address all correspondence to Henry L. Lew, MD, PhD; Chief, PM\&R Service, VA Boston Healthcare System, 150 South Huntington Avenue, Boston, MA 02130; 617-3237700; fax: 857-203-5680. Email: henry.lew@va.gov

DOI:10.1682/JRRD.2009.01.0006 
the two most prevalent and functionally disabling conditions may be posttraumatic stress disorder (PTSD) and chronic pain. This "polytrauma clinical triad" of chronic pain, PTSD, and persistent postconcussive symptoms (PPCS) presents a significant diagnostic and therapeutic challenge to healthcare providers.

With the extreme forces used in combat and the resultant physical injuries, pain from trauma or injury is, not surprisingly, a significant problem in combat returnees. Commonly reported locations of pain include the head, back, legs, and shoulders [4-6]. Pain that persists for an extended period of time (i.e., >3-6 months) and initially accompanies a disease process or bodily injury that has subsequently resolved or healed may be referred to as chronic pain [7]. Chronic pain is often associated with other problems, including functional disability, psychological distress, as well as family discord and vocational issues.

Many combat returnees also report symptoms of acute combat stress disorder or PTSD. While symptoms of acute combat stress may occur after prolonged exposure to military theater conditions, these symptoms often gradually remit by themselves within 30 days. However, servicemembers who continue to exhibit these symptoms for more than 30 days may meet criteria for PTSD. A recent study demonstrated that of 103,788 Operation Iraqi Freedom/Operation Enduring Freedom (OIF/OEF) veterans seen at Department of Veterans Affairs (VA) facilities, approximately 25 percent received one or more distinct mental health diagnoses, with the single most common diagnosis being PTSD [8]. PTSD can occur following exposure to an event that is, or is perceived to be, threatening to the well-being of oneself or another person. Symptoms of PTSD may include reexperiencing the event in the form of intrusive thoughts; nightmares; avoidance of thoughts, people, and places that resemble the traumatic event; and symptoms of hyperarousal, including heightened startle, poor sleep, attentional difficulties, or anger [9].

TBI is a "signature injury" in this modern warfare [10]. Considerable attention has been paid to the dramatic nature of severe TBI. However, the vast majority of military servicemembers are actually at a much higher risk of sustaining a mild TBI [11]. While postconcussive symptoms often resolve within a month of the injury [12], for some individuals the symptoms can last for months or years. Given that the exact cluster of symptoms varies substantially across postconcussion patients, use of the term "syndrome" or "disorder" may not be accurate or clinically useful. Instead, it has been suggested that the unique individual pattern of symptoms should be documented and be the focus of treatment. Throughout this article, persistent and ongoing physical, cognitive, or behavioral difficulties lasting longer than 3 months following a mild TBI are referred to as PPCS [4].

To meet the healthcare needs of returning veterans, the VHA established the Polytrauma System of Care, consisting of 5 Polytrauma Rehabilitation Centers (PRCs), 22 Polytrauma Network Sites (PNSs), 80 Polytrauma Support Clinical Teams, and about 50 Polytrauma Points of Contact. Level 1 PRCs provide acute, comprehensive, inpatient rehabilitation, while Level 2 PNSs provide interdisciplinary, specialized, postacute rehabilitation services in consultation with the PRCs as needed. Several studies have reported on the prevalence of TBI, chronic pain, and PTSD among OIF/OEF veterans receiving care at Level 1 and 2 facilities. A study by Sayer et al. found that in a sample of 188 combat injured servicemembers treated at a Level 1 PRC, 93.0 percent incurred a combat-related TBI, 81.0 percent report a pain problem, and 52.6 percent received some type of mental health services [13]. In another study of 50 OIF/OEF veterans treated at a Level 1 PRC, 80 percent incurred a combat-related TBI, 96 percent reported at least one pain problem, and 44 percent reported experiencing PTSD [5]. Clark and colleagues discussed the complex array of pain issues and the challenges related to the reliable assessment and care management of servicemembers being seen in the PRC [14]. Lew et al. found that in a sample of the first 62 patients evaluated at a Level 2 PNS, 97 percent reported three or more PPCS (i.e., headache, dizziness, fatigue), 97 percent complained of chronic pain, and 71 percent met criteria for PTSD [4]. Taken together, these studies underscore the high prevalence rates of these conditions among the most severely injured servicemembers from the wars in Iraq and Afghanistan.

However, no study to date has reported the extent to which these three conditions occur in combination with one another. This study examines the coprevalence rates of chronic pain, PTSD, and PPCS in returning OIF/OEF veterans referred to a Level 2 PNS. When chronic pain was present, additional analyses were performed to identify the specific pain sites.

\footnotetext{
*Vanderploeg R, personal communication; February 9, 2009.
} 


\section{METHODS}

After obtaining approval from the local institutional review board, we systematically reviewed the VA Computerized Medical Record System for 340 OIF/OEF veterans seen at a PNS between January 1, 2007, and October 27, 2008 (22 months). All 340 OIF/OEF veterans enrolled for care in this setting during the period were included in the analyses.

Every OIF/OEF returnee's first point of contact with any VA clinic would automatically trigger an electronic clinical reminder for TBI screening. The screening includes (1) history of injury events that may increase risk for TBI, (2) symptoms related to alteration of consciousness appearing immediately after the traumatic event, (3) new or worsening TBI symptoms after the traumatic event, and (4) persistence of these symptoms into the present. The presence of all four screening criteria constitutes a "positive TBI screen" and an automatic referral to the local PNS for further evaluation. The PNS typically comprises a physiatrist, a neuropsychologist, a nurse, a case manager/clinical coordinator, a physical therapist, a speech-language pathologist, and an occupational therapist. Following clinical evaluation by the physiatrist and case manager/clinical coordinator, other members of the team were consulted as needed. For this project, each medical record was individually reviewed by an independent PhD-level clinical psychologist with training and expertise in the assessment and diagnosis of chronic pain, PTSD, and PPCS. The data obtained for this study were based on the second-level TBI comprehensive evaluation conducted by the designated physiatrist of the PNS. Only formal diagnoses reached by the physiatrist of the PNS and placed in the structured progress note were included in the study analyses. Chronic pain was defined as persisting reports of pain in one or more parts of the body for more than 3 months after onset [15]. The diagnosis of PTSD was reached based on criteria established by the American Psychiatric Association [9]. For this study, PPCS was defined by the presence of an initial TBI (evidence of exposure to a trauma that resulted in an initial alteration or loss of consciousness with partial or total amnesia for the events immediately preceding and/or following the event), followed by three or more PPCS lasting for more than 3 months postinjury [16]. The categories of pain locations used for this study were obtained from a previous study defining the characteristics of returning veterans [4].

\section{RESULTS}

We conducted frequency analyses to determine the extent to which chronic pain, PTSD, or PPCS was diagnosed in our sample of OIF/OEF veterans. The results indicated that of the 340 veterans in our sample, 12 (3.5\%) did not meet criteria for chronic pain, PTSD, or PPCS. Our results indicated a high prevalence of all three conditions in the sample, with chronic pain, PTSD, and PPCS being present in 81.5, 68.2, and 66.8 percent, respectively. As shown in Figure 1, the frequency at which these three conditions were present in isolation was significantly lower than the frequency at which they were present in combination with one another $\left(\chi^{2}=(2, N=\right.$ $340)=33.88, p>0.001)$. In fact, analyses demonstrate that 42.1 percent of the sample was diagnosed with all three conditions simultaneously.

Given the high prevalence of chronic pain in this sample, we conducted additional analyses to determine the most common locations of chronic pain symptoms reported. As summarized in Figure 2, the most common chronic pain locations were the back (58\%) and head (55\%). These were followed by chronic pain involving the shoulder (21\%), neck (19\%), and knee (18\%).

\section{DISCUSSION}

The results of this study are consistent with previous research describing the high rates of chronic pain, PTSD, and PPCS in OIF/OEF veterans at a Level 2 PNS [4]. Our observation of a different rate of PPCS in our sample compared with the results of other studies may reflect variations in the OIF/OEF population sampled or individual differences in the criteria employed in the various settings. Despite the differences, data from the present study clearly demonstrate the extent to which chronic pain, PTSD, and PPCS overlap with one another. Consistent with Lew et al., the results of this study also support that back pain and headache are the most common pain symptoms reported by OIF/OEF veterans [4]. These results are clinically significant because they underscore the complexity of presenting complaints in returning servicemembers and veterans, which would support the importance of a multidisciplinary team approach to these patients' assessment and treatment [17-18]. 


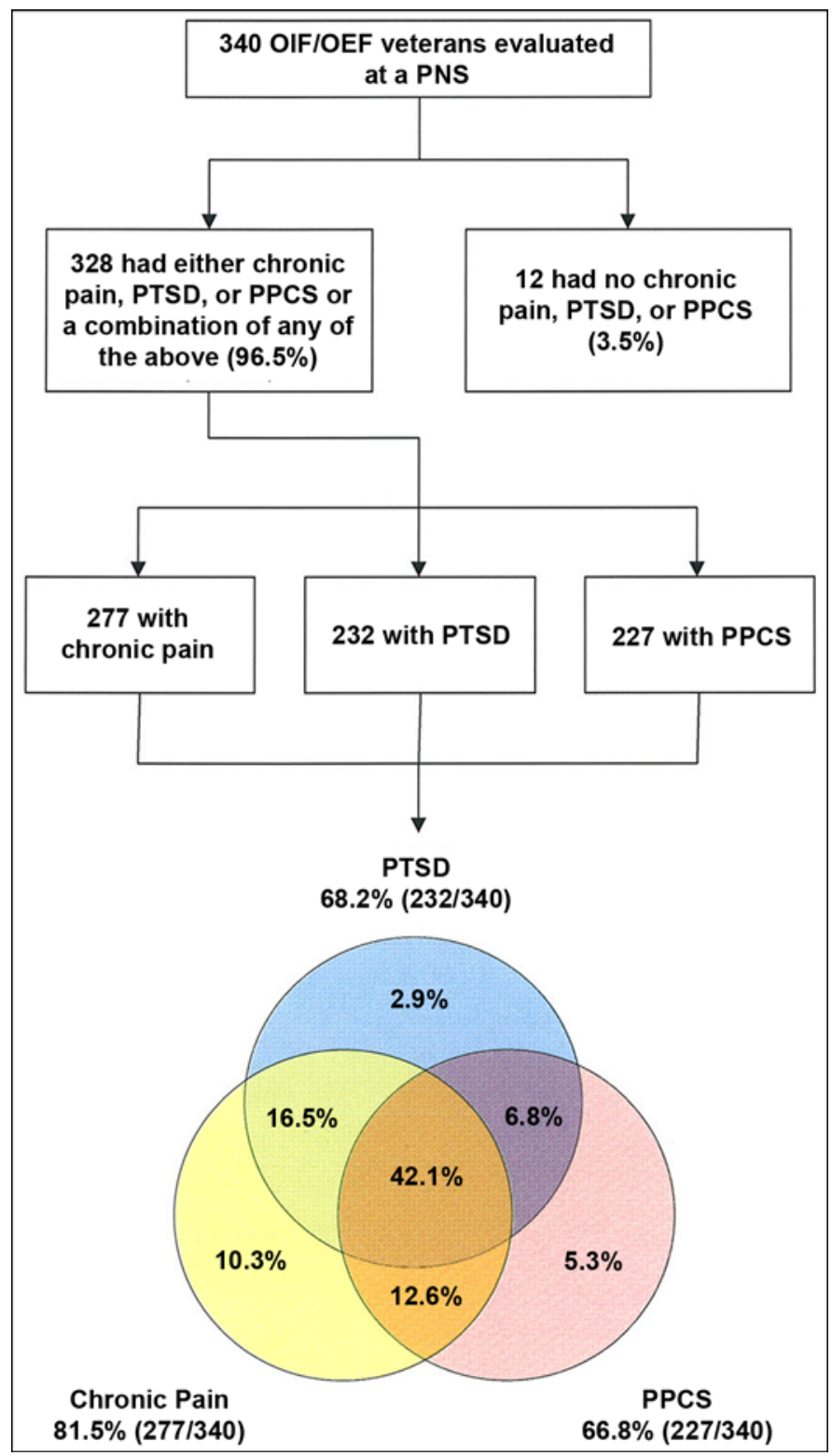

Figure 1.

The polytrauma clinical triad: Distribution of patients with chronic pain, posttraumatic stress disorder (PTSD), and persistent postconcussive symptoms (PPCS) in a sample of 340 Operation Iraqi Freedom/Operation Enduring Freedom (OIF/OEF) veterans evaluated at Department of Veterans Affairs Boston Polytrauma Network Site (PNS).

Closer inspection reveals that many symptoms and problems associated with chronic pain, PTSD, and PPCS overlap. For example, poor concentration is often associated with both PTSD and PPCS, while depressed mood is common in both chronic pain and PTSD. This overlap can challenge a clinician's ability to accurately attribute symptoms and arrive at an accurate diagnosis. It may also

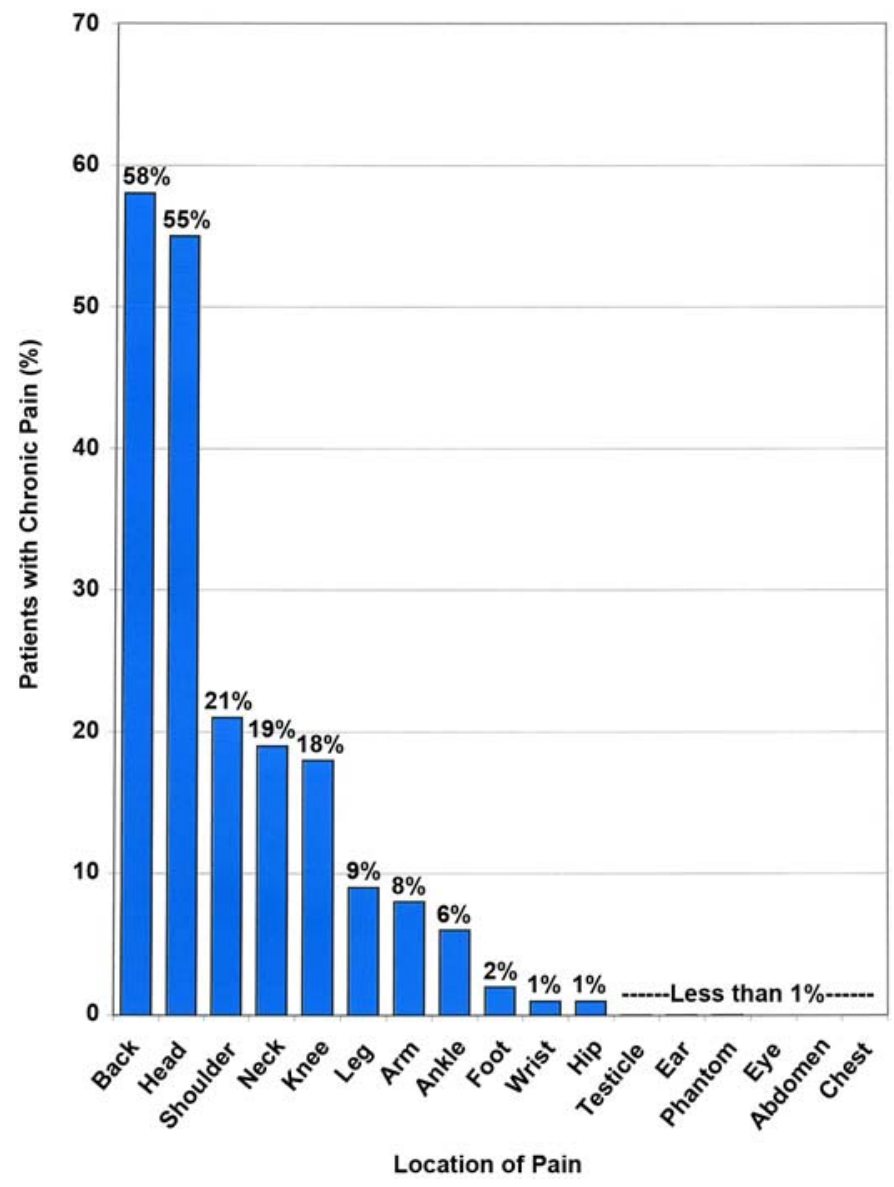

Figure 2.

Pain distribution in sample of 340 Operation Iraqi Freedom/Operation Enduring Freedom veterans evaluated at Department of Veterans Affairs Boston Polytrauma Network Site.

make choosing the most appropriate treatment plan difficult, which can subsequently result in decreased treatment efficacy and patient satisfaction. Therefore, it is critical that clinicians and researchers work as a team to integrate their understanding of the relationships among these problems so that treatment can be appropriate and well-coordinated.

The ways in which chronic pain, PTSD, and PPCS may interact with one another warrant further investigation. For example, sleep issues, cognitive problems, or emotional issues associated with PTSD may negatively impact one's ability to cope with PPCS. Similarly, PPCS are likely detrimental to factors that increase one's resilience in overcoming PTSD or adaptively coping with a chronic pain condition. In a similar manner, the experience of a chronic pain flare-up may trigger PTSD-related thoughts, while PTSD symptoms such as hyperarousal 
may increase pain intensity [19-20]. Research funded by VA Rehabilitation Research and Development is currently investigating the efficacy of an integrated approach to the psychological management of chronic pain, PTSD, and PPCS. More translational research is needed to better understand the interrelationships among chronic pain, PTSD, and PPCS and the ways in which existing evidencebased treatments can be modified to meet the needs of these veterans.

The results of this study have clinical applications because the data revealed not only the individual occurrence rates but also the level of coprevalence of chronic pain, PTSD, and PPCS among OIF/OEF returnees at a VA facility. While the sample size of this study $(n=340)$ is larger than that of a recent report on the PNS patient population $(n=62)$ [4], several limitations bear mentioning. During the chart review for this study, we did not differentiate "upper" from "lower" back pain. However, in the updated TBI PNS clinical evaluation template, back pain is differentiated into upper and lower back pain. It is likely that once back pain is subcategorized into lower and upper areas, headache will be the number one complaint for pain. Another limitation of this study is that it did not assess for the presence of substance abuse or dependence, which are likely important issues for OIF/OEF veterans. Finally, while the International Classification of Diseases-Revision 9 criteria related to the diagnosis of chronic pain are quite clear, PPCS and PTSD may be challenging to diagnose and differentiate. Follow-up studies should consider using validated measures of PTSD (e.g., Clinician Administered PTSD Scale [21]) and neuropsychological assessments of PPCS when attempting to replicate or validate the results of this study.

It is important to consider that some OIF/OEF returnees have other health insurance plans and thus do not seek healthcare through the VA. Of those veterans who have sought healthcare with the VA and completed the TBI screening questionnaire, approximately 20 percent have answered positive to all four screening questions. ${ }^{*}$ Our data represent only those veterans who answered positive to all four screening questions, agreed to undergo further evaluation, and then completed a comprehensive evaluation at the PNS. The data did not include those veterans who declined the recommended evaluation after a "positive TBI screen" or those who agreed to further evaluation but did

\footnotetext{
*Veterans Integrated Service Network Support Services Center, monthly report; July 2009. Available from: http://vssc.med.va.gov/.
}

not show up to the clinic. The healthcare needs of these veterans remain to be explored. Thus, we must (1) provide follow-up care to those veterans who presented to the PNS clinic with physical, cognitive, or emotional issues, and (2) reach out to those not represented in this study to determine effective ways of delivering assistance to veterans who may potentially be in need of help.

\section{CONCLUSIONS}

The results of this study suggest that the polytrauma clinical triad of chronic pain, PTSD, and PPCS is highly prevalent among OIF/OEF veterans seeking healthcare through the VA. The data also indicate that each of these problems rarely occurs by itself; in fact, the three conditions most often occur in combination with one another. Overall, healthcare providers and researchers who specialize in helping OIF/OEF veterans will need to work together to gain a broader understanding of how the experience of war-related injury has affected our returning soldiers, to recognize the importance of treating the entire person rather than a particular disorder, and to prioritize the development of innovative and effective treatment approaches for this population.

\section{ACKNOWLEDGMENTS}

\section{Author Contributions:}

Study concept and design: H. L. Lew. Acquisition of data and statistical analysis: J. D. Otis, C. Tun. Analysis and interpretation of data: J. D. Otis, C. Tun.

Drafting of manuscript: H. L. Lew, J. D. Otis.

Critical revision of manuscript for important intellectual content: H. L. Lew, J. D. Otis, C. Tun, R. D. Kerns, M. E. Clark, D. X. Cifu.

Study Supervision: H. L. Lew.

Financial Disclosures: The authors have declared that no competing interests exist.

Funding/Support: This material was based on work supported by the VA Rehabilitation Research and Development Service, Merit Review Project B5008R.

Additional Contributions: We gratefully acknowledge Drs. David Chandler, Lucille Beck, Alex Ommaya, Barbara Sigford, Joel Kupersmith, Robert Ruff, Michael Selzer, Nina Sayer, Rodney Vanderploeg, Joel Scholten, Shane McNamee, Steven Scott, Peter Hsu, Terrence Keane, and Michael Charness for their support and advice during the preparation of this article.

Participant Follow-Up: The authors do not plan to inform participants of the publication of this study. 


\section{REFERENCES}

1. Lew HL. Rehabilitation needs of an increasing population of patients: Traumatic brain injury, polytrauma, and blastrelated injuries. J Rehabil Res Dev. 2005;42(4):xiii-xvi. [PMID: 16320135] DOI:10.1682/JRRD.2005.01.0124

2. Okie S. Traumatic brain injury in the war zone. N Engl J Med. 2005;352(20):2043-47. [PMID: 15901856] DOI:10.1056/NEJMp058102

3. Warden D. Military TBI during the Iraq and Afghanistan wars. J Head Trauma Rehabil. 2006;21(5):398-402. [PMID: 16983225] DOI:10.1097/00001199-200609000-00004

4. Lew HL, Poole JH, Vanderploeg RD, Goodrich GL, Dekelboum S, Guillory SB, Sigford B, Cifu DX. Program development and defining characteristics of returning military in a VA Polytrauma Network Site. J Rehabil Res Dev. 2007; 44(7):1027-34. [PMID: 18075959] DOI:10.1682/JRRD.2007.05.0073

5. Clark ME, Bair MJ, Buckenmaier CC 3rd, Gironda RJ, Walker RL. Pain and combat injuries in soldiers returning from Operations Enduring Freedom and Iraqi Freedom: Implications for research and practice. J Rehabil Res Dev. 2007;44(2):179-94. [PMID: 17551872]

DOI:10.1682/JRRD.2006.05.0057

6. Gironda RJ, Clark ME, Massengale JP, Walker RL. Pain among veterans of Operation Enduring Freedom and Iraqi Freedom. Pain Med. 2006;7:339-43. [PMID: 16898945] DOI:10.1111/j.1526-4637.2006.00146.X

7. Merskey H, Bogduk N, editors; International Association for the Study of Pain Task Force on Taxonomy. Classification of chronic pain: Descriptions of chronic pain syndromes and definitions of pain terms. Seattle (WA): IASP Press; 1994.

8. Seal KH, Bertenthal D, Miner CR, Sen S, Marmar C. Bringing the war back home: Mental health disorders among 103,788 US veterans returning from Iraq and Afghanistan seen at Department of Veterans Affairs facilities. Arch Intern Med. 2007;167(5):476-82. [PMID: 17353495] DOI:10.1001/archinte.167.5.476

9. American Psychiatric Association. Diagnostic and statistical manual of mental disorders: DSM-IV. Washington (DC): American Psychiatric Association; 1994.

10. Defense and Veterans Brain Injury Center. Understanding traumatic brain injury [Internet]. Washington (DC): Defense and Veterans Brain Injury Center. Available from: http://www.dvbic.org/education.php.

11. Lew HL, Poole, JH, Alvarez S, Moore W. Soldiers with occult traumatic brain injury. Am J Phys Med Rehabil. 2005;84(6):393-98. [PMID: 15905652] DOI:10.1097/01.phm.0000163703.91647.a7
12. Belanger HG, Curtiss G, Demery JA, Lebowitz BK, Vanderploeg RD. Factors moderating neuropsychological outcomes following mild traumatic brain injury: A metaanalysis. J Int Neuropsychol Soc. 2005;11(3):215-27.

[PMID: 15892898] DOI:10.1017/S1355617705050277

13. Sayer NA, Cifu DX, McNamee S, Chiros CE, Sigford BJ, Scott S, Lew HL. Rehabilitation needs of combat-injured servicemembers admitted to the VA Polytrauma Rehabilitation Centers: The role of PM\&R in the care of wounded warriors. PM R. 2009;1(1):23-28. [PMID: 19627869] DOI:10.1016/j.pmrj.2008.10.003

14. Clark ME, Scholten JD, Walker RL, Gironda RJ. Assessment and treatment of pain associated with combat-related polytrauma. Pain Med. 2009;10(3):456-69. [PMID: 19416437] DOI:10.1111/j.1526-4637.2009.00589.x

15. World Health Organization. Manual of the international statistical classification of diseases, injuries, and causes of death. Geneva (Switzerland): World Health Organization; 1977.

16. American Congress of Rehabilitation Medicine. Definition of mild traumatic head injury. J Head Trauma Rehabil. 1993; 8(3):86-87. DOI:10.1097/00001199-199309000-00010

17. Lew HL, Cifu DX, Sigford B, Scott S, Sayer N, Jaffee MS. Team approach to diagnosis and management of traumatic brain injury and its comorbidities. J Rehabil Res Dev. 2007; 44(7):vii-xi. [PMID: 18075945$]$

18. Lew HL, Poole JH, Guillory SB, Salerno RM, Leskin G, Sigford B. Persistent problems after traumatic brain injury: The need for long term follow-up and coordinated care. J Rehabil Res Dev. 2006;43(2):vii-x. [PMID: 16847779] DOI:10.1682/JRRD.2006.05.0054

19. Otis JD, Keane TM, Kerns RD. An examination of the relationship between chronic pain and post-traumatic stress disorder. J Rehabil Res Dev. 2003;40(5):397-405. [PMID: 15080224]

20. Otis JD, Pincus DB, Keane TM. Comorbid chronic pain and posttraumatic stress disorder across the lifespan: A review of theoretical models. In: Young G, Kane, A, Nicholson K, editors. Psychological knowledge in court: PTSD, pain, and TBI. Boston (MA): Springer; 2006. p. 242-68. DOI:10.1007/0-387-25610-5_14

21. Blake DD, Weathers FW, Nagy LM, Kaloupek DG, Klauminzer G, Charney DS, Keane TM. A clinician rating scale for assessing current and lifetime PTSD: The CAPS-1. Behav Ther. 1990;13:187-88.

Submitted for publication January 14, 2009. Accepted in revised form April 6, 2009. 